\title{
Comparison of the Anthelmintic Efficacy of Three Commercial Products against Ascarids and Capillaria SPP. in Fighting Cocks
}

\author{
Froylán Ibarra-Velarde, Cristina Guerrero-Molina, Yolanda Vera-Montenegro, Yazmín Alcalá-Canto, \\ Evangelina Romero-Callejas
}

Departamento de Parasitología, Facultad de Medicina Veterinaria y Zootecnia de la, Universidad Nacional Autónoma de Mexico, Coyoacán, México City, Mexico.

Email: Ibarraf@servidor.unam.mx

Received February 9 ${ }^{\text {th }}, 2011$; March 20 ${ }^{\text {th }}, 2011$; April 20 ${ }^{\text {th }}, 2011$.

\begin{abstract}
The aim of the present study was to evaluate the anthelmintic efficacy of three commercial compounds against ascarids and Capillaria spp. in naturally infected fighting cocks from Mexico. First experiment-Forty cocks were selected on the basis of eggs per gram (EPG) counts quantified by the McMaster method. On day 0 the birds were divided into four groups of 10 cocks, each subjected to the treatments. Group 1 received a single oral dose of $1 \mathrm{mg}$ of ivermectin, $25 \mathrm{mg}$ of praziquantel and $40 \mathrm{mg}$ of fenbendazole given in tablets according to body weight (b.w). Group 2 was treated with a single oral dose of $1 \mathrm{mg}$ of ivermectin, $25 \mathrm{mg}$ of praziquantel and $40 \mathrm{mg}$ of fenbendazole given in tablets/b.w. but formulated with a different excipient. Group 3 received a single tablet containing $0.2 \mathrm{mg}$ of abamectin and $30 \mathrm{mg}$ of albendazole. Group 4 served as a non-treated control. Fecal analyses were carried out on days 0 (day of treatment), 7 , 14, 21 and 28, being collected from the floor where the cocks were individually caged. Efficacy was measured on the percentage of egg reduction from day 0 with respect the EPG counts from the control group. In a second experiment the study was similarly performed using another cock-farm located at approximately $300 \mathrm{~km}$ away from the first one. Results indicated an overall efficacy of 100\%, 94.0\% and 100\% for groups 1, 2 and 3 in the first experiment and 100\%, $100 \%, 100 \%$ for groups 1, 2 and 3 of the 2nd experiment, respectively. It is concluded that all drugs used exerted high efficacy in fighting cocks naturally infected with helminths.
\end{abstract}

Keywords: Anthelmintic Efficacy, Commercial Drugs, Fighting Cocks

\section{Introduction}

In Mexico the cockfight is a popular activity frequently carried out in places for combat called "palenques". The fights generally take place on holidays, national festivities or week-ends throughout the country. Important to note is the fact that the cockfight is also a growing industry which provides employment and involves thousands of people engaged in the gambling on the outcome of of this festive activity.

However, one of the important factors which hampers the aggressive performance of fighting cocks at the time of combat is the decrease of energy commonly caused by different parasitic infections. On the other hand, there is very limited information on the use of drugs that can remove helminths from the cocks. The present study was aimed at the evaluation of the antelmintic efficacy of three commercial compounds against Ascarids and Capillaria spp. in fighting cocks from two different farms.

\section{Material and Methods}

\subsection{First Experiment}

\subsubsection{Location of the Study}

This study was carried out at the farm "El Colorado", located in the municipality of Tulancingo, in the state of Hidalgo, Mexico, (central part of Mexico).

\subsubsection{Study Animals}

Forty adult and young fighting cocks with no deworming background of at least 6 months were selected for inclusion in the trial. They were chosen on the basis of egg counts per gram (EPG) by using the quantitative McMaster method. All animals were individually caged, 
being feed on peleted food, water being supplied ad libitum

\subsubsection{Drugs for Evaluation}

1)Vermicell-Gallos (Laboratorios ANDOCI, S.A de C.V. ${ }^{\circledR}$ ), formulated in tablets containing $1 \mathrm{mg}$ de ivermectin, $25 \mathrm{mg}$ of praziquantel and $40 \mathrm{mg}$ of fenbendazole.

2)Endovet-Gallos. (Revetmex ${ }^{\circledR}$ ), formulated in tablets containing $1 \mathrm{mg}$ de ivermectin, $25 \mathrm{mg}$ of praziquantel and $40 \mathrm{mg}$ of fenbendazole, being formulated with an excipient different from the previous one.

3)Trifen-Plus (Laboratorios Aranda ${ }^{\circledR}$ ), formulated in tablets each containing $0.2 \mathrm{mg}$ of abamectin and $30 \mathrm{mg}$ of Albendazole.

\subsubsection{Animal Identification}

All groups of animals were identified with plastic numbered and colored rings. Each cock was always kept in an individual cage.

\subsubsection{Conduction of the Study}

The forty selected cocks were divided into 4 groups of 10 animals each for treatment.

Group 1 received Vermicell-Gallos at a single oral dose of 1 tablet $/ 2.5 \mathrm{~kg} / \mathrm{b} . \mathrm{w}$.

Group 2 was treated with Endovet-Gallos at a single oral dose of 1 tablet $/ 2.5 \mathrm{~kg} / \mathrm{b} . \mathrm{w}$.

Group 3 received Trifen-Plus at a single oral dose of 1 tablet $/ 1 \mathrm{~kg} / \mathrm{b} . \mathrm{w}$.

Group 4 served as a non-treated control.

\subsubsection{Fecal Analyses}

Fecal individual fresh samples of feces were taken from the study animals on days 0 (day of treatment), 7, 14, 21 and 28 being transported to our laboratory for inmmediate analysis.

\subsection{Efficacy}

Efficacy was measured on the percentage of egg reduction of the treated animals relative to the non-treated control group following the formula of [1].

$$
\text { Effcacy }=\frac{\text { No. de EPG in the non-treated group }- \text { No. de EPG in the treated group }}{\text { No. de EPG in the non-treated group }} \times 100
$$

\subsubsection{Statistical Analyses}

With the aim of determining posible differences among groups on each date of sampling, the obtained data was subjected to the Kruskall-Wallis test. In addition, in order to compare the quantity of EPG in each group from the initial to the last samplings, the Wilcoxon rank test was employed.

\subsubsection{Second Experiment}

In a second experiment, the study was similarly performed using the same drugs and treatments with the difference that the study was undertaken in another cock-farm called "La Quinta Portuguesa”, located at approximately $300 \mathrm{~km}$ from first one.

40 fighting cocks positive to ascarids were selected from 125 animals available were divided into 4 groups of 10 animals each ready for treatment as in Experiment one. The same measurements of anthelmintic efficacy were similarly undertaken so as to be compared with those of the first experiment.

\section{Results}

General results can be seen in Tables 1 to 4 .

\subsection{First Experiment}

Group 1 showed a gradual reduction of EPG after treatment, the efficacy exerted being of $97.0 \%, 91.0 \%, 100 \%$ and $100 \%$, for days 7, 14, 21 and 28, after treatment, respectively (Table 1).

Group 2 showed percentages of egg reduction of
$97.0 \%, 71.0 \%, 97.0 \%$ and $94.0 \%$ for days $7,14,21$ y 28 , respectively (Table 1).

Group 3 showed an efficacy of $100 \%$ for days 7, 14, 21 and 28 after treatment, respectively (Table 1).

Group 4 constantly mantained egg shedding during the experiment. The maximum mean number of EPG was 2350 ( $\bar{x} 235$ ) and the minimum 950 ( $\bar{x}$ 95). (Table 2).

\subsection{Statistical Analyses}

\subsubsection{Comparison Among Treatments in Each One of the Days of Fecal Sampling}

On day 0 , no statistical differences were found among

Table 1. Percentage of helminths-EPG reduction postreatment with three commercial anthelmintics in fighting cocks from Tulancingo, Mexico.

\begin{tabular}{ccccccc}
\hline Groups & Dose & Tx & $\begin{array}{c}\text { Days after } \\
\text { treatment }\end{array}$ & & & \\
\hline $\begin{array}{c}(\mathrm{n}=10 \\
\text { cocks/group) }\end{array}$ & 1 tablet & 0 & 7 & 14 & 21 & 28 \\
& $\begin{array}{c}2.5 \\
\text { kg/b.w }\end{array}$ & - & 97 & 91 & 100 & 100 \\
Group 1 $^{*}$ & $\begin{array}{c}2.5 \\
\text { kgoup 2 }\end{array}$ & - & 97 & 71 & 97 & 94 \\
Group 3*w & 1 kg/b.w & - & 100 & 100 & 100 & 100 \\
$\begin{array}{c}\text { Group 4 } \\
\text { (Control) }\end{array}$ & 0 & - & - & - & - & - \\
\hline
\end{tabular}

Tx = Treatment; b.w. = bod y weight; ${ }^{*} 1 \mathrm{mg}$ ivermectin, $25 \mathrm{mg}$ praziquantel, $40 \mathrm{mg}$ fenbendazole; ${ }^{* *} 1 \mathrm{mg}$ ivermectin, $25 \mathrm{mg}$ praziquantel, $40 \mathrm{mg}$ fenbendazole (formulated with different excipient); ${ }^{* * *} 0.2 \mathrm{mg}$ avamectin, $30 \mathrm{mg}$ albendazole. 
Table 2. Statistical analysis of the comparison on the efficacy of three commercial compounds against helminths of fighting cocks from Tulancingo, Mexico.

\begin{tabular}{|c|c|c|c|c|c|}
\hline Groups & Day 0 & Day 7 & Day 14 & Day 21 & Day 28 \\
\hline & \multicolumn{5}{|c|}{ Average number of eggs \pm Standard Deviation } \\
\hline Group 1 & $195^{\mathrm{a}, 1} \pm 28.3$ & $5^{\mathrm{a}, 1} \pm 5.0$ & $15^{\mathrm{a}, 1} \pm 15.1$ & $0^{\mathrm{a}, 2}$ & $0^{\mathrm{a}, 2}$ \\
\hline Group 2 & $160^{\mathrm{a}, 1} \pm 23.3$ & $5^{\mathrm{a}, 1} \pm 5.0$ & $50^{\mathrm{a}, 1} \pm 36.5$ & $5^{\mathrm{a}, 2} \pm 5.0$ & $10^{\mathrm{a}, 2} \pm 6.7$ \\
\hline Group 3 & $160^{\mathrm{a}, 1} \pm 23.3$ & $0^{\mathrm{a}, 1}$ & $0^{\mathrm{a}, 2}$ & $0^{\mathrm{a}, 2}$ & $0^{\mathrm{a}, 1}$ \\
\hline Group 4 (Control) & $175^{\mathrm{a}, 1} \pm 22.7$ & $235^{\mathrm{b}, 2} \pm 33.4$ & $210^{\mathrm{b}, 1} \pm 23.3$ & $125^{\mathrm{b}, 1} \pm 20.1$ & $95^{\mathrm{b}, 2} \pm 17.4$ \\
\hline
\end{tabular}

Mean in the same column with the same letter are statistically equal; Mean in the same row with equal number are equal to the average on day 0.

the EPG of the experimental groups ( $<<0.717)$ (Table 2).

On day 7, statistical differences were found on the quantity of EPG of group 4 (non-treated control) with each one of the treated groups $(p<0.0001)$.

Results with the same tendency were found on days 14 , 21 , and 28 , respectively.

\subsubsection{Comparison of Fecal Samplings between Treatments}

Treament 1. Comparisons of each one of the average fecal samples from day 0 with the different days of samplings (7, 14, 21, and 28) showed a statistical difference using the Wilcoxon test of signed ranks ( $\mathrm{p}<0.0085)$.

With regard to treatments 2 and 3 , the results obtained were similar to those found in group 1.

On the other hand, Group 4 showed no statistical differences on the average EPG obtained on day 0 when compared with the average EPG from days 7, 14 and 21. However, statistical difference were determined when fecal sampling of day 28 was analyzed ( $<<0.014$ ). (Table 2).

In addition, during the study of the group of Vermicell-Gallos, two cocks were positive to Dermanysuss spp. and another one was parasitized with some lice. After treatment these animals were observed to be negative. However, since the size sample of these artropods was
Table 3. Percentage of helminths-EPG reduction postreatment with three commercial anthelmintics in fighting cocks from La Portuguesa, Texcoco, Mexico.

\begin{tabular}{|c|c|c|c|c|}
\hline Groups & Dose & $\mathrm{Tx}$ & $\begin{array}{c}\text { Days after } \\
\text { treatment }\end{array}$ & \\
\hline $\begin{array}{c}(\mathrm{n}=10 \\
\text { cocks/group) }\end{array}$ & 1 tablet & 0 & 7 & $\begin{array}{lll}14 & 21 \quad 28\end{array}$ \\
\hline Group $1^{*}$ & $2.5 \mathrm{~kg} / \mathrm{b} . \mathrm{w}$ & - & 100 & 100100100 \\
\hline Group $2^{* *}$ & $2.5 \mathrm{~kg} / \mathrm{b} . \mathrm{w}$ & - & 100 & 100100100 \\
\hline Group $3^{* * *}$ & $1 \mathrm{~kg} / \mathrm{b} . \mathrm{w}$ & - & 100 & 100100100 \\
\hline Group 4 (Control) & 0 & - & - & $-\quad-$ \\
\hline
\end{tabular}

Tx = Treatment; b.w. = body weight; ${ }^{*} 1 \mathrm{mg}$ ivermectin, $25 \mathrm{mg}$ praziquantel, $40 \mathrm{mg}$ fenbendazole; ${ }^{* *} 1 \mathrm{mg}$ ivermectin, $25 \mathrm{mg}$ praziquantel, $40 \mathrm{mg}$ fenbendazole (formulated with different excipient); ${ }^{* * * *} 0.2 \mathrm{mg}$ avamectin, $30 \mathrm{mg}$ albendazole.

very small, these results should be recorded as additional data that need to be further confirmed.

\subsubsection{Second Experiment}

All treated groups from "La Quinta Portuguesa” showed an EPG reduction of 100\%, demonstrating an oustanding efficacy (Table 3).

According to the Kruskal-Wallis test, on day 0 no statistical difference on EPG was found between treated 
Table 4. Statistical analysis of the comparison on the efficacy of three commercial compounds against helminths of fighting cocks from La Portuguesa, Texcoco, Mexico.

\begin{tabular}{|c|c|c|c|c|c|}
\hline Groups & Day 0 & Day 7 & Day 14 & Day 21 & Day 28 \\
\hline \multicolumn{6}{|c|}{ Average number of eggs \pm Standard Deviation (Percentage of Efficacy) } \\
\hline Group 1 & $290^{\mathrm{a}, 1} \pm 53.1$ & $0^{\mathrm{a}, 1}$ & $0^{\mathrm{a}, 1}$ & $0^{\mathrm{a}, 1}$ & $0^{\mathrm{a}, 1}$ \\
\hline Group 2 & $275^{\mathrm{a}, 1} \pm 58.1$ & $0^{\mathrm{a}, 2}$ & $0^{\mathrm{a}, 2}$ & $0^{\mathrm{a}, 2}$ & $0^{\mathrm{a}, 2}$ \\
\hline Group 3 & $265^{\mathrm{a}, 1} \pm 47.8$ & $0^{\mathrm{a}, 2}$ & $0^{\mathrm{a}, 2}$ & $0^{\mathrm{a}, 2}$ & $0^{\mathrm{a}, 2}$ \\
\hline Group 4 (Control) & $295^{\mathrm{a}, 1} \pm 41.1$ & $305^{\mathrm{b}, 1} \pm 41.8$ & $310^{\mathrm{b}, 1} \pm 47.0$ & $322^{\mathrm{b}, 1} \pm 55.4$ & $250^{\mathrm{b}, 1} \pm 65.1$ \\
\hline
\end{tabular}

Mean in the same column with the same letter are statistically equal; Mean in the same row with equal number are equal to the average on day 0.

groups and the control group ( $\mathrm{p}<0.898)$. (Table 4)

On day 7 statistical differences between the quantity of EPG were observed in group 4 with regard to all other groups ( $\mathrm{p}<0.0001)$.

Results with a similar tendency were found on days 14 , 21, and 28 after treatment, respectively.

\subsubsection{Comparison of fecal Samplings between Treatments}

Comparison of day 0 with each one of the average days of sampling $(7,14,21$, and 28$)$ showed significant differences, using the Wilcoxon rank test $(\mathrm{p}<0.005)$.

Results were similar when treatments of groups 1,2 and 3 were compared.

In group 4, no significant difference was observed in the mean EPG from day 0, as compared with the average EPG from days 7, 14, 21 and 28 (Table 4)

\section{Discussion}

Information regarding the use of anthelmintics in game birds is very scanty.

Ref. [2] demonstrated that the administration of fenbendazole reduced natural nematode infection in pheasants and partridges.

In the present experiment, the data obained from both farms showed that a combined dose of ivermectin/ praziquantel/fenbendazole given at the producer recommended dose was highly effective in decreasing the percentage reduction of EPG and therefore the reduction of gastrointestinal nematode infections in common fowl (Gallus gallus) raised as fighting cocks.

It was also demonstrated that even when VermicellGallos or Endovet-Gallos were formulated with a different excipient, they showed no statistical difference in efficacy. Nevertheless, it is important to point out that they have shown better efficacy than ivermectin administered alone [3-5] praziquantel [6,7] for fenbendazole used as a single treatment [8-12].

On the other hand, the efficacy of the combined treatment of $0.2 \mathrm{mg}$ of abamectin plus $30 \mathrm{mg} / \mathrm{kg}$ of albendazole were enough to remove all ascarids and some Capillaria, since no helminth eggs were found a few days after treatment. Perhaps a slight advantage of Trifen-plus is that only two drugs are needed to obtain similar efficacy and therefore cost decrease on treatments may be better when these drugs are used. However, a drawback for this compound is that if the cocks of either farm under study have a cestode infection, the use of the ivermectin/praziquantel/fenbendazole combination may be advisable instead since praziquantel is the drug of choice to remove this type of helminths.

It is important to mention that the efficacy of albendazole on its own against bird parasites has already been described by [13]. Nevertheless, as far as we know, no previous reports regarding the anthelmintic efficacy of an abamectin/albendazole combination are available. The slight difference in the percent reduction of egg output observed between the combination regimens using distinct excipients is an important topic for future investigations. They might correlate bioavailability and anthelmintic efficacy by the analysis of ingredient concentrations and their main metabolites by high performance liquid chromatography.

With regard to the relation of cost-benefit, although all treatments for fighting cocks are not expensive, but it is important to know the time of the year when helminth infections are spread in higher proportion in the birds so that a suitable treatment schedule may be established.

On the other hand, the effect of albendazole on enzy- 
mes from common species of poultry-infecting nematodes has been demonstrated [13]; however, as far as we know, combination regimes employing an ivermectin/ praziquantel/fenbendazole formulation with these anthelmintics in fighting cocks have not as yet been reported.

These results have demonstrated that combined dosing of some commercial anthelmintics provides highly promising efficacy against gastrointestinal nematodes on fighting cooks maintaining good health status, which is highly required for better performance in the fighting arena.

\section{Conclusions}

The combined administration of either ivermectin/praziquantel/fenbendazole or abamectin/albendazole administered in tablets at the producer's recommended dose exerted high efficacy against Ascarids and Capillaria spp. in naturally infected fighting cocks

\section{Acknowledgements}

Study financially supported by Laboratorios ANDOCI, S.A. de C.V.

\section{References}

[1] J. Eckert, G. Schneiter, K. Wolf, "Fasinex (Triclabendazole)-A New Fasciolicide," Berl Munch Tierarztl Wochenschr, Vol. 91, 1984, pp. 349-326.

[2] R. Kirsch, "Treatment of Nematodiasis in Poultry and Game Birds with Fenbendazole,” Avian Diseases, Vol. 28, No. 2, 1984, pp. 311-318. doi:10.2307/1590337

[3] A. Oksanen, S. Nikander, "Ivermectin as a Bird Anthelmintictrials with Naturally Infected Domestic Fowl," Zentralbl Veterinarmed Reihe B, Vol. 36, No. 7, 1989, pp. 495-499.

[4] R. W. Miller, "Use of Ivermectin to Control the Lesser Mealworm (Coleoptera: Tenebrionidae) in a Simulated Poultry Broiler House,” Poultry Science, Vol. 69, Vol. 8, 1990, pp. 1281-1284.

[5] R. L. Sharma, T. K. Bhat, "Short communication Anthelmintic Activity of Ivermectin against Experimental Ascaridia galli Infection in Chickens,” Veterinary Parasi- tology, Vol. 37, No. 3-4, 1990, pp. 307-314. doi:10.1016/0304-4017(90)90014-3

[6] M. Rajendran, A. M. Nadakal, "The Efficacy of Praziquantel (Droncit R) against Raillietina tetragona (Molin, 1958) in Domestic Fowl," Veterinary Parasitology, Vol. 26 No. 3-4, 1988, pp. 253-260. doi:10.1016/0304-4017(88)90093-3

[7] I. E. Nurelhuda, E. E. Elowni, T. Hassan, "Anthelmintic Activity of Praziquantel on Raillietina tetragona in Chickens,” Parasitology Research, Vol. 75, No. 8, 1989, pp. 655-656. doi:10.1007/BF00930965

[8] G. S. Senyonga, "Efficacy of Fenbendazole against HelMinth Parasites of Poultry in Uganda," Tropical Animal Health and Production, Vol. 14, Vol. 3, 1982, pp. 163-166. doi:10.1007/BF02242148

[9] T. A. Yazwinski, P. Andrews, H. Holtzen, B. Presson, N. Wood, Z. Johnson, "Dose-titration of Fenbendazole in the Treatment of Poultry Nematodiasis,” Avian Diseases, Vol. 30, No. 4, 1986, pp. 716-718. doi:10.2307/1590574

[10] S. M. Taylor, J. Kenny, A. Houston, S. A. Hewitt, "Efficacy, Pharmacokinetics and Effects on Egg-Laying and Hatchability of Two dose Rates of In-Feed Fenbendazole for the Treatment of Capillaria Species Infections in Chickens,” Veterinary Record, Vol. 133, No. 21, 1993, pp. 519-521. doi:10.1136/vr.133.21.519

[11] J. E. Sander, R. D. Schwartz, "Evaluation of Three Water-Suspensible Formulations of Fenbendazole against Ascaridia galli Infection in Broiler Chickens," Avian Diseases, Vol. 38, No. 2, 1994, pp. 350-353. doi:10.2307/1591961

[12] L. M. Pote, C. E. Couvillion, R. W. Keirs, R. D. Schwartz, R. F. Taylor, J. H. Hackathorn, L. K. Johnson, "Dose Titration to Confirm the Level of Fenbendazole for Control of Raillietina cesticillus in Broiler Chickens," Avian Diseases, Vol. 36, No. 3, 1992, pp. 722-724. doi:10.2307/1591772

[13] R. K. Sharma, K. Singh, K. K. Saxena, “The Effect of LeVamisole and Albendazole on Some Enzymes of Ascaridia galli and Heterakis gallinae," Veterinary Parasitology, Vol. 30, No. 3, 1989, pp. 213-222. doi:10.1016/0304-4017(89)90017-4 